\title{
Effect of Formulated Plant Extracts and Oils on Population Density of Phytophthora nicotianae in Soil and Control of Phytophthora Blight in the Greenhouse
}

\author{
John H. Bowers and James C. Locke, United States Department of Agriculture-Agricultural Research Service \\ (USDA-ARS), U. S. National Arboretum, Floral \& Nursery Plants Research Unit, Beltsville, MD 20705
}

\begin{abstract}
Bowers, J. H., and Locke, J. C. 2004. Effect of formulated plant extracts and oils on population density of Phytophthora nicotianae in soil and control of Phytophthora blight in the greenhouse. Plant Dis. 88:11-16.

Formulated plant extracts and oils were investigated for control of diseases caused by Phytophthora spp. Soil infested with chlamydospores of Phytophthora nicotianae was treated by incorporating 1,5 , and $10 \%$ aqueous emulsions of formulations containing clove oil, neem oil, pepper extract and mustard oil, cassia extract, synthetic cinnamon oil, or the fungicide metalaxyl. Population densities of P. nicotianae were determined at 0 (before treatment), 1, 3, 7 , 14, and 21 days after treatment. Treatment of the soil with 5 and $10 \%$ aqueous emulsions resulted in significant $(P<0.05)$ differences among treatment mean values at each assay date. After 1 day, population densities were reduced to below the limit of detection $\left(<0.04 \mathrm{CFU} / \mathrm{cm}^{3}\right)$ in soil treated with $10 \%$ aqueous emulsions of two pepper extract-mustard oil formulations and two cassia extract formulations, and near the limit of detection for a synthetic cinnamon oil formulation. Over time, populations of $P$. nicotianae were detected in the assay; however, after 21 days, populations of $P$. nicotianae in soil treated with one of the pepper extract-mustard oil formulations still were not detected. Formulations of clove oil, another pepper extract-mustard oil combination, the two cassia extracts, and the synthetic cinnamon oil reduced populations 98.4 to $99.9 \%$ after 21 days compared with the nontreated control soil. The neem oil formulation and metalaxyl did not reduce pathogen populations at any rate tested. In the greenhouse after 35 days, $10 \%$ aqueous emulsions of a pepper extract-mustard oil formulation, a cassia extract, and the synthetic cinnamon oil formulation suppressed disease development in periwinkle 93.0 to $96.7 \%$ compared with the nontreated infested soil. The observed reduction in the pathogen population and significantly more healthy plants in the greenhouse indicates that these formulations of plant extracts and oils could have important roles in biologically based management strategies for control of diseases caused by $P$. nicotianae.
\end{abstract}

Additional keywords: essential oil of mustard

Phytophthora nicotianae Breda de Haan (= P. parasitica Dastur) (7) is one of the most widespread and destructive soilborne plant pathogens. Erwin and Ribeiro (7) list 301 host species with a worldwide distribution. This pathogen causes root, stem, and crown rots, as well as fruit and foliar

Corresponding author: J. H. Bowers

E-mail: john_bowers@comcast.net

Current address of J. H. Bowers: Blights, Lesions, \& Assoc., Laurel, MD 20707.

Current address of J. C. Locke: USDA-ARS, University of Toledo, Toledo, $\mathrm{OH} 43606$.

Mention of a trademark, proprietary product, or vendor does not constitute a guarantee or warranty of the product by the USDA, and does not imply its approval to the exclusion of other products or vendors that also may be suitable.

Accepted for publication 23 June 2003.

Publication no. D-2003-1020-03R

This article is in the public domain and not copyrightable. It may be freely reprinted with customary crediting of the source. The American Phytopathological Society, 2004. blights from splash dispersal of propagules from soil, on many agronomic and horticultural plants in seed beds, nurseries, fields, and landscape plantings. Symptoms of the disease on many hosts develop rapidly during periods of high soil moisture associated with prolonged, rainy weather or frequent irrigation. Control measures frequently involve targeting pathogen propagules in soil with fungicide drenches to reduce initial inoculum. However, disease control options using pesticides are being lost.

We recently reported on the reduction of soil populations of Fusarium oxysporum and Verticillium dahliae and disease control of Fusarium wilt in the greenhouse when soil was treated with formulated plant extracts $(1,3)$. Additionally, we demonstrated that combining natural plant extracts and biological control organisms may be a viable strategy to control soilborne pathogens (2). Because we have shown that the formulated plant extracts are effective against chlamydospores and conidia of $F$. oxysporum and microsclerotia of $V$. dahliae, we were interested in exploring the range of their effectiveness in other microbial groups. Therefore, the objective of the present research was to evaluate several formulated plant extracts and essential oils for their effectiveness in reducing populations of $P$. nicotianae and controlling disease development in periwinkle. If natural plant products can reduce populations of soilborne plant pathogens and control disease development, then these plant extracts have potential as environmentally safe alternatives and as components in integrated pest management programs.

\section{MATERIALS AND METHODS}

Inoculum preparation. $P$. nicotianae isolate $\mathrm{Pn}-21$, originally isolated from periwinkle (5), was used in all experiments. Isolate Pn-21 did not grow on medium amended with metalaxyl at 10 or 100 $\mu \mathrm{g} / \mathrm{ml}$. Chlamydospore inoculum was prepared according to the procedure of Tsao (14). Mycelial mats were grown in $25 \mathrm{ml}$ of $5 \%$ clarified V8 juice broth $(4,7)$ in 150 $\mathrm{ml}$ prescription bottles incubated horizontally at $24^{\circ} \mathrm{C}$. After 7 days, the medium was decanted and $125 \mathrm{ml}$ of sterile deionized water was added to each bottle and incubated vertically at $18^{\circ} \mathrm{C}$ for 3 to 4 weeks. Chlamydospores were harvested by rinsing the cultures two to three times with deionized water and homogenizing in a small blender for $1 \mathrm{~min}$. The mycelial suspension then was ground in a glass tissue grinder to further break up the mycelium. The suspension was filtered through two layers of cheesecloth and sonicated in a water bath for two 30-s periods to disrupt any remaining viable mycelium. Microscopic examination verified that no cytoplasm remained in the mycelial fragments. Inoculum from 10 bottles was thoroughly incorporated into 5.0 liters of steampasteurized, composted soil previously sifted through a 2-mm sieve. Pasteurized soil was subjected to natural recolonization by airborne microorganisms in the greenhouse by exposure to the greenhouse environment for at least 3 weeks before infestation with $P$. nicotianae. Infested soil was incubated in the lab at room temperature (approximately 20 to $22^{\circ} \mathrm{C}$ ) for 5 to 7 days before being assayed for population density of $P$. nicotianae. Inoculum density was evaluated by dilution plating onto PARPH medium containing $10 \mathrm{mg}$ of pimaricin, $250 \mathrm{mg}$ of ampicillin, $10 \mathrm{mg}$ of rifampicin, $100 \mathrm{mg}$ of pentachloronitrobenzene, $50 \mathrm{mg}$ of hymexazol, and $17 \mathrm{~g}$ of cornmeal agar 
(Difco Laboratories, Detroit) in 1.0 liter of deionized water $(8,12)$. Based on this assay, the soil inoculum was thoroughly mixed with known volumes of the pasteurized soil to give the desired inoculum density for use in experiments. Inoculum density was confirmed in the experimental soil by dilution plating samples onto the PARPH medium after soil mixing. Pasteurized, uninfested soil was used as a control in all experiments.

Treatments. The experimental treatments for both the population density experiments in the lab and the disease control experiments in the greenhouse were identical (Table 1). Experimental treatments were (i) uninfested soil, only water added as a check for residual populations of $P$. nicotianae (not included in analysis); (ii) infested soil, only water added; (iii) clove oil $(70 \%$ formulated clove oil; Thermo Trilogy Corp., Columbia, MD); (iv) neem oil (90\% formulated neem oil, Triact 90EC, Thermo Trilogy Corp.); (v) and (vi) pepper extract-mustard oil combination (formulated chili pepper extract and essential oil of mustard from two sources; Insect Control Concentrate, Champon's 100\% Natural Products Inc., Pompano Beach, FL; and Greenshield Compounds, NaturalPest FX, Inc., Washington, D.C.); (vii and viii) cassia extract (two formulations of the extract of cassia tree, Cut In [20\% cinnamaldehyde] and Tolcap [22\% cinnamaldehyde], Abion Co., Tokyo); (ix) synthetic cinnamon oil (30\% cinnamaldehyde, Cinnamite, Mycotech, Butte, MT); and (x) metalaxyl fungicide (Subdue 2E; Syngenta, Greensboro, NC). The formulated extracts and oils were mixed thoroughly into soil and compared as 1, 5, and 10\% aqueous emulsions in separate trials of the experiment. Metalaxyl was mixed thoroughly in soil at low, medium, and high labeled rates (0.364, 0.728 , and $1.46 \mu \mathrm{l}$ a.i. per $150 \mathrm{~cm}^{3}$ of soil, corresponding with $0.25,0.5$, and $1.0 \mathrm{fl}$. oz. of product per cubic yard, respectively) in the 1,5 , and $10 \%$ extract trials, respectively.

Population density in the laboratory. For laboratory experiments, $P$. nicotianae was incorporated into soil (previously sifted through a 2-mm sieve) at an inoculum density of approximately 200 chlamydospores $/ \mathrm{cm}^{3}$ of soil. This high inoculum density was used in order to observe treatment differences. Aliquots $\left(150 \mathrm{~cm}^{3}\right)$ of the infested and control soil were placed in sterile 400-ml beakers and covered with a double layer of aluminum foil. Soil was treated by thoroughly mixing with a spatula $5.0 \mathrm{ml}$ of 1,5 , or $10 \%$ aqueous emulsions of formulated extracts into the soil in each of three beakers (replications of the experimental unit) per treatment. Population densities of $P$. nicotianae were determined using dilution plate techniques at 0 (before soil treatment), 1, 3, 7, 14, and 21 days after soil treatment. Soil (sample unit, $15 \mathrm{~cm}^{3}$ ) from each beaker (replication) was placed in the appropriate amount of $0.1 \%$ water agar and serially diluted. From the appropriate dilution, $1 \mathrm{ml}$ was pipetted onto the surface of each of five petri plates containing PARPH medium. Plates were incubated at room temperature in the dark for 3 days, at which time colonies of $P$. nicotianae were counted. The average population density for the three replications per treatment at each assay date was calculated and used in the analysis of treatment effects. Nine trials of the experiment were conducted and all extract and concentration combinations were repeated at least once in different trials.

Disease control in the greenhouse. Phytophthora blight of periwinkle (Catharanthus roseus (L.) G. Don) caused by $P$. nicotianae was used as a model system in greenhouse studies. In greenhouse experiments, soil inoculum was incorporated into soil (not sifted) using a cement mixer at an inoculum density of $7.0 \mathrm{CFU} / \mathrm{cm}^{3}$ of soil. At this inoculum density, 50 to $80 \%$ of the plants died in preliminary tests (unpublished data). After a 5-day incubation period, soil was treated by incorporating 84 $\mathrm{ml}$ of 1,5 , or $10 \%$ aqueous emulsions of formulated extracts into 2.5 liters of soil (experimental unit, one replicate per trial of the experiment) using a Hobart mixer (Hobart Corp., Troy, OH). The rates are equivalent to $5.0 \mathrm{ml}$ of aqueous emulsion in $150 \mathrm{~cm}^{3}$ of soil as described above for the population density experiment. Treated soil was placed in double polyethylene bags that were then closed tightly and incubated as above for an additional 7 days. Metalaxyl was incorporated similarly at the same labeled rates as above. After the incubation period, soil from each treatment (2.5 liters) was placed in $206.4-\mathrm{cm}$ diameter standard plastic pots, and one 4to 6-week-old seedling of periwinkle cv. Parasol (Park Seed Co., Greenwood, SC) was transplanted to the soil in each pot. Pots were placed randomly on the greenhouse bench. Disease symptoms (wilting and the presence of characteristic stem cankers) and mortality were assessed 3, 7, 10 , and 14 days after transplanting, and weekly thereafter. The number of symptomless plants was recorded for each extract and concentration combination at each assay date and expressed in terms of the proportion of symptomless plants. Six trials of the experiment, with all formulations and concentration combinations repeated at least once in different trials, were conducted at different times of the year with different greenhouse temperatures.

Analysis. Data from the laboratory population density experiments were transformed as $\log _{10} \mathrm{CFU} / \mathrm{cm}^{3}$ of soil before analysis. Data from the disease control experiments in the greenhouse were transformed as the arcsine of the square root of the proportion of symptomless plant stand. Both laboratory and greenhouse experiments were analyzed as repeated-measure designs and analysis of variance determined using the MIXED procedure in SAS (Statistical Analysis System, Cary, NC). Time was the repeated variable (not a continuous regressor variable) and trial of the experiment the random variable in all analyses. The fixed effects were formulation and concentration. For the purpose of analysis, concentration was nested within formulation because the fungicide concentrations were different than the formulated extract concentrations. Means of all pairwise comparisons, both among concentrations of a single formulated extract and among formulated extracts at a single concentration, were tested using Fisher's pro-

Table 1. Experimental treatments on the population density of Phytophthora nicotianae in soil and control of Phytophthora blight on periwinkle ${ }^{z}$

\begin{tabular}{ll}
\hline Treatment & Description \\
\hline Control & No P. nicotianae, no extract treatment (- control) \\
Nontreated & P. nicotianae control, no extract treatment (+ control) \\
Clove & $70 \%$ clove oil, Thermo Trilogy Corp., Columbia, MD \\
Neem & $90 \%$ neem oil, Triact 90EC, Thermo Trilogy Corp. \\
Pepper extract-mustard oil 1 & Formulated chili pepper extract and essential oil of mustard, Insect Control \\
& Concentrate, Champon's 100\% Natural Products Inc., Pompano Beach, FL \\
Pepper extract-mustard oil 2 & Formulated chili pepper extract and essential oil of mustard, \\
& Greenshield Compounds, NaturalPest FX, Inc., Washington, D.C. \\
Cassia extract 1 & Cassia tree extract (20\% cinnamaldehyde), Cut In, Abion Co., Tokyo \\
Cassia extract 2 & Cassia tree extract (22\% cinnamaldehyde), Tolcap, Abion Co., Tokyo \\
Cinnamon oil & Synthetic cinnamon oil (30\% cinnamaldehyde), Cinnamite, Mycotech, Butte MT \\
Metalaxyl & Subdue 2E, CIBA-GEIGY, Greensboro, NC \\
\hline
\end{tabular}

${ }^{\mathrm{z}}$ Soil was treated with 1,5 , or $10 \%$ aqueous emulsions of the formulated products as described in the text. Rates of metalaxyl for low, medium, and high were $0.364,0.728$, and $1.46 \mu \mathrm{l}$ a.i. per $150 \mathrm{~cm}^{3}$ soil, respectively. 
tected least significant difference with significance determined at $P<0.05$ for population density experiments in the lab and $P<0.10$ for disease control experiments in the greenhouse. The significance level for the greenhouse experiment was determined before analysis based on the observed variation in plant growth among trials of the experiment due to external greenhouse variables (13).

\section{RESULTS}

Significant differences existed among formulated extracts, extract concentration, and time for both the population density experiments in the lab (Table 2) and disease control experiments in the greenhouse (Table 3). There were significant interactions with time for both formulated extracts and extract concentration in the population density experiment, indicating that changes over time were not the same over all extract formulations or extract concentrations (Table 2). Significant interactions also existed in the disease control experiments for the interaction of time and formulated extract, but not for the interaction of time and extract concentration (Table 3). Changes in disease control over time varied among formulated extracts, but were similar over extract concentration.

Population density in the laboratory. Soil treated with $1 \%$ aqueous emulsions of several formulated extracts, oils, or metalaxyl statistically $(P \leq 0.05)$ reduced populations of $P$. nicotianae compared with the nontreated control soil 21 days after soil treatment (Table 4; Fig. 1). Soil populations of $P$. nicotianae were reduced 49.7 and $55.6 \%$ for the formulated clove and neem oils, respectively. The two pepper extract-mustard oil formulations resulted in statistically greater population density of P. nicotianae 21 days after soil treatment.

Soil treated with 5\% aqueous emulsions of both formulations of pepper extract and mustard oil, cassia extract 1 , and synthetic cinnamon oil formulations significantly $(P$ $\leq 0.05)$ reduced populations of $P$. nicotianae 3 days after treatment 90.6, 99.9, 88.3, and $92.4 \%$, respectively, compared with the nontreated control soil (Fig. 1). After this initial reduction, larger populations were detected over time. Twenty-one days after soil treatment, the formulation of neem oil, both formulations of pepper extract and mustard oil, and synthetic cinnamon oil formulation significantly reduced populations by 53.6, 74.0, 50.7, and $83.6 \%$, respectively, compared with the nontreated control soil (Table 4).

Treatment of soil with $10 \%$ aqueous emulsions of the formulated extracts and oils resulted in significant $(P \leq 0.05)$ reductions in the population density of $P$. nicotianae (Fig. 1). Population densities were reduced to below the limit of detection of the assay $\left(0.04 \mathrm{CFU} / \mathrm{cm}^{3}\right) 1$ day after soil was treated with both formulations of the pepper extract and mustard oil,
Table 2. Repeated-measures analysis of variance for the effect of treatment of soil with formulated plant extracts and oils or metalaxyl and time in days on population density of Phytophthora nicotianae $^{\mathrm{z}}$

\begin{tabular}{lrrr}
\hline Source & df & $\boldsymbol{F}$ value & $\boldsymbol{P}>\boldsymbol{F}$ \\
\hline Formulation & 8 & 49.25 & $<0.0001$ \\
Concentration (formulation) & 15 & 62.09 & $<0.0001$ \\
Day & 4 & 3.58 & 0.0068 \\
Day $\times$ formulation & 32 & 6.20 & $<0.0001$ \\
Day $\times$ concentration (formulation) & 54 & 5.97 & $<0.0001$ \\
\hline
\end{tabular}

${ }^{\mathrm{z}}$ Data were analyzed as $\mathrm{CFU} / \mathrm{cm}^{3}$ of soil.

Table 3. Repeated-measures analysis of variance for the effect of treatment of soil with formulated plant extracts and oils or metalaxyl and time in days on symptomless plants of periwinkle growing in soil infested with Phytophthora nicotianae ${ }^{\mathrm{z}}$

\begin{tabular}{lrrr}
\hline Source & df & $\boldsymbol{F}$ value & $\boldsymbol{P} \boldsymbol{F}$ \\
\hline Formulation & 7 & 16.74 & $<0.0001$ \\
Concentration (formulation) & 14 & 10.53 & $<0.0001$ \\
Day & 6 & 138.32 & $<0.0001$ \\
Day $\times$ formulation & 36 & 2.59 & $<0.0001$ \\
Day $\times$ concentration (formulation) & 50 & 1.17 & 0.2172 \\
\hline
\end{tabular}

${ }^{\mathrm{z}}$ Data were transformed using the arcsine-square root transformation before analysis.

Table 4. Soil population densities of Phytophthora nicotianae and healthy plant stand of periwinkle growing in infested soil at the conclusion of the experiments as affected by soil treatment with formulated plant extracts and oils or metalaxyl ${ }^{\mathrm{w}}$

\begin{tabular}{|c|c|c|}
\hline Rate, treatment ${ }^{\mathrm{x}}$ & Population density of $P$. nicotianae ${ }^{\mathrm{y}}$ & Percent healthy plant stand ${ }^{z}$ \\
\hline \multicolumn{3}{|l|}{$1 \%$} \\
\hline Nontreated & $167.5 \mathrm{~cd}$ & 0.0 \\
\hline Clove & $84.3 \mathrm{e}$ & 0.0 \\
\hline Neem & $74.3 \mathrm{e}$ & $2.5 \mathrm{a}$ \\
\hline Pep/Must 1 & $262.0 \mathrm{a}$ & 0.0 \\
\hline Pep/Must 2 & $247.3 \mathrm{ab}$ & 0.0 \\
\hline Cassia 1 & $129.7 \mathrm{~d}$ & 0.0 \\
\hline Cassia 2 & $185.3 \mathrm{abc}$ & $\ldots$ \\
\hline Cinnamon & $107.3 \mathrm{~d}$ & 0.0 \\
\hline Metalaxyl (low) & $171.3 \mathrm{bc}$ & $23.8 \mathrm{a}$ \\
\hline \multicolumn{3}{|l|}{$5 \%$} \\
\hline Nontreated & $167.5 \mathrm{~b}$ & 0.0 \\
\hline Clove & $140.3 \mathrm{bc}$ & $13.0 \mathrm{~b}$ \\
\hline Neem & 77.7 ef & $5.0 \mathrm{~b}$ \\
\hline Pep/Must 1 & $43.5 \mathrm{f}$ & $40.0 \mathrm{a}$ \\
\hline Pep/Must 2 & $82.5 \mathrm{de}$ & 0.0 \\
\hline Cassia 1 & $134.1 \mathrm{bc}$ & 0.0 \\
\hline Cassia 2 & $191.7 \mathrm{a}$ & $\ldots$ \\
\hline Cinnamon & $27.5 \mathrm{f}$ & $33.3 \mathrm{ab}$ \\
\hline Metalaxyl (medium) & $131.3 \mathrm{~cd}$ & $37.5 \mathrm{a}$ \\
\hline \multicolumn{3}{|l|}{$10 \%$} \\
\hline Nontreated & $167.5 \mathrm{a}$ & 0.0 \\
\hline Clove & $2.6 \mathrm{c}$ & $41.0 \mathrm{~b}$ \\
\hline Neem & $105.3 \mathrm{~b}$ & $3.8 \mathrm{c}$ \\
\hline Pep/Must 1 & $<\mathrm{LD}$ & $93.3 \mathrm{a}$ \\
\hline Pep/Must 2 & $0.04 \mathrm{~d}$ & $5.0 \mathrm{c}$ \\
\hline Cassia 1 & $0.5 \mathrm{c}$ & $93.0 \mathrm{a}$ \\
\hline Cassia 2 & $0.7 \mathrm{c}$ & $\ldots$ \\
\hline Cinnamon & $0.4 \mathrm{c}$ & $96.7 \mathrm{a}$ \\
\hline Metalaxyl (high) & $117.0 \mathrm{ab}$ & $62.5 \mathrm{~b}$ \\
\hline
\end{tabular}

${ }^{w}$ Under each concentration of emulsion, mean values in the same column followed by the same letter are not significantly different at $P=0.05$ for the population density experiment and $P=0.10$ for the disease control experiment based on multiple comparisons of least-square means using the Bonferroni method; $\angle \mathrm{LD}=$ populations of $P$. nicotianae were below the limit of detection in the soil dilution assays $\left(0.04 \mathrm{CFU} / \mathrm{cm}^{3}\right.$ of soil).

x Soil was treated with 1,5 , or $10 \%$ aqueous emulsions of the formulated products as described in the text. Rates of metalaxyl for low, medium, and high were $0.364,0.728$, and $1.46 \mu 1$ a.i. per 150 $\mathrm{cm}^{3}$ of soil, respectively. (The Cassia 2 treatment was not included in the greenhouse experiments.)

${ }^{y}$ Mean values are $\mathrm{CFU} / \mathrm{cm}^{3}$ of soil 21 days after soil treatment. Data represent the average of nine trials of the experiment with three replications per treatment per trial. Average population density at 0 time (before treatment) was $213.4 \mathrm{CFU} / \mathrm{cm}^{3}$ of soil.

${ }^{z}$ Mean values are percent symptomless plants 35 days after transplanting. Data represent the average of six trials of the experiment with 20 pots per treatment and one plant per pot. For analysis, data were transformed as the arcsine of the square root of symptomless plants expressed as a proportion. 
and both formulations of the cassia extracts. The synthetic cinnamon oil formulation reduced pathogen populations to the limit of detection. Population densities continued to be undetectable for 21 days in soil treated with the pepper extractmustard oil 1 formulation, and for 14 days in soil treated with the pepper extractmustard oil 2 formulation. There was a general increase after the initial decline in population densities after 3 days for the two cassia extracts and synthetic cinnamon oil formulations as observed in soil treated with $5 \%$ aqueous emulsions. After 21 days, clove oil, pepper extract-mustard oil 2, cassia extracts 1 and 2, and synthetic cinnamon oil formulations significantly reduced $(P \leq 0.05)$ populations of $P$. nico-

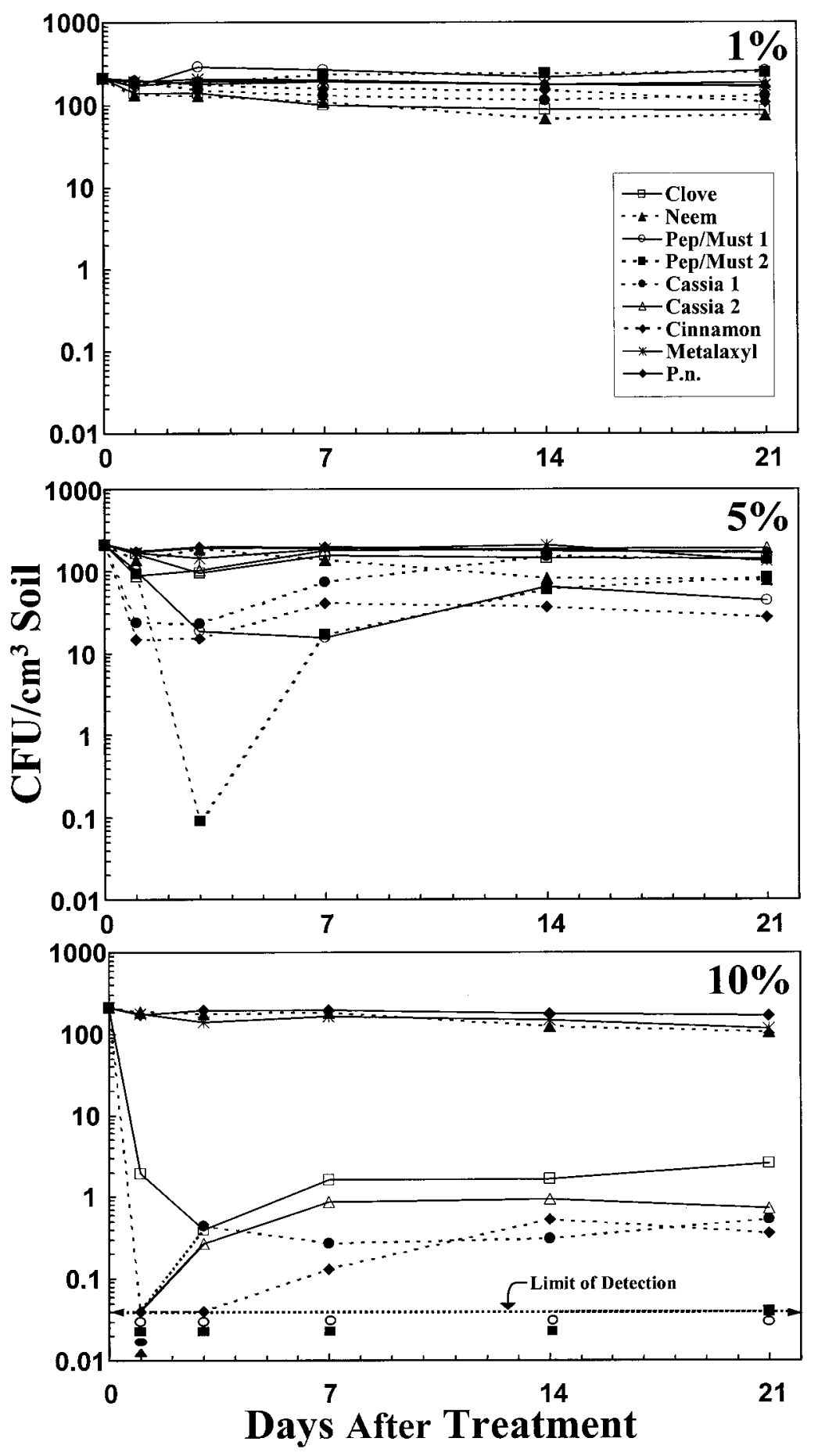

Fig. 1. Population density of Phytophthora nicotianae $\left(\mathrm{CFU} / \mathrm{cm}^{3}\right.$ of soil) after soil treatment with formulated plant extracts and oils or metalaxyl. Each point represents the mean of repeated trials of the experiment with three replications per trial. Soil was treated with 1, 5, and $10 \%$ (top, middle, and bottom, respectively) aqueous emulsions of the formulated plant extracts and oils, or with metalaxyl at $0.364,0.728$, and $1.46 \mu \mathrm{l}$ a.i. per $150 \mathrm{~cm}^{3}$ of soil, respectively. Symbols below the limit of detection represent populations of $P$. nicotianae that were not detected in the dilution plate assay for those treatments at the times indicated. tianae compared with the nontreated control soil 98.4, 99.9, 99.7, 99.6, and 99.8\%, respectively, and below the limit of detection for soil treated with the pepper extract-mustard oil 1 formulation (Table 4).

Disease control in the greenhouse. The percentage of healthy, symptomless plants growing in soil treated with $1 \%$ aqueous emulsions declined in all botanical formulation treatments until there were few, if any, plants without symptoms (0 to $2.5 \%$ ) 35 days after transplanting (Fig. 2). Soil treated with the low rate of metalaxyl did provide some control in the greenhouse 35 days after transplanting $(23.8 \%$ healthy stand); however, due to experimental variation, healthy stand was not significantly $(P$ $=0.103$ ) greater than that for the neem formulation (2.5\% healthy stand; Table 4$)$.

Disease control in the greenhouse when soil was treated with $5 \%$ aqueous emulsions of the formulated extracts and oils was greater than when soil was treated with $1 \%$ aqueous emulsions (Fig. 2). However, the same general decline occurred in the symptomless plant stand over time. Soil treated with $5 \%$ aqueous emulsions of the pepper extract-mustard oil 1 and synthetic cinnamon oil formulations resulted in disease control that was not significantly $(P>0.1)$ different from the metalaxyl treatment $(40.0,33.3$, and $37.5 \%$, respectively) 35 days after transplanting (Table 4). Treatment of soil with $5 \%$ aqueous emulsions of the clove and neem oil formulations resulted in significantly $(P \leq$ $0.1)$ less plant stand (13.0 and $5.0 \%$ healthy stand, respectively). Treatment of the soil with pepper extract-mustard oil 2 and cassia extract 1 formulations resulted in $100 \%$ disease incidence ( $0 \%$ plant stand) 35 days after transplanting.

Treatment of soil with $10 \%$ aqueous emulsions of the pepper extract-mustard oil 1 formulation, cassia extract 1 , and synthetic cinnamon oil formulations resulted in significantly $(P \leq 0.1)$ greater healthy plant stand $(93.3,93.0$, and $96.7 \%$ plant stand, respectively) than with either the clove oil formulation or metalaxyl treatments (41.0 and $62.5 \%$ plant stand, respectively) 35 days after transplanting (Table 4). The neem oil and pepper extract-mustard oil 2 formulations did not control disease in the greenhouse (3.8 and $5.0 \%$ plant stand, respectively), even though the pepper extract-mustard oil 2 formulation reduced population densities significantly in laboratory experiments.

\section{DISCUSSION}

Certain formulations of plant-derived (botanical) extracts and oils were found to affect soil populations of $P$. nicotianae and reduce disease development on periwinkle. Experimental conditions were optimized for survival of $P$. nicotianae in soil and disease development in the greenhouse. Despite favorable conditions for the pathogen, formulations of pepper extract and 
mustard oil, cassia extract, and cinnamon oil (abeit synthetic) reduced pathogen populations and resulted in higher healthy plant stand compared with the pathogenonly control. These extracts also were shown to reduce populations of $F$. $o x$ ysporum (3) and V. dahliae (1), and to control disease in the greenhouse. Botanical extracts and oils also have promise to be utilized with other control measures, such as biological control microorganisms (2).

Although much of the activity of certain plant extracts or oils may be inherent in the chemical ingredients in the material, the formulation of the extract or oil ultimately may determine effectiveness for disease control. The two cassia extract formulations were very similar, and their active ingredients almost in the same concentration (20 and $22 \%$ cinnamaldehyde). These two formulations also resulted in similar reductions in populations of $P$. nicotianae in soil. On the other hand, the two pepper extract and mustard oil formulations were from different sources and differed in composition and concentration of the active ingredients (actual specifications of the formulations are unknown). Both reduced populations of $P$. nicotianae to low levels and, at times, below the limit of detection of our assay, when incorporated into soil as $10 \%$ aqueous emulsions, but only pepper extract-mustard oil 1 formulation controlled disease in the greenhouse. Whereas pepper extract-mustard oil 2 formulation apparently reduced the pathogen population to near undetectable levels in the lab assay, propagules of $P$. nicotianae evidently survived in the greenhouse experiments and were able to cause considerable disease on the susceptible periwinkle variety.

In a previous report, we hypothesized that these materials and formulations may be more fungistatic than fungicidal (3). The general trend when both 5 and $10 \%$ aqueous emulsions were incorporated into soil was that populations were initially recovered at a low level over 1 to 3 days, and then appeared to increase or level off at a somewhat higher and constant value range. Pathogen populations in soil treated with a $5 \%$ aqueous emulsion of pepper extract-mustard oil 2 appeared to declined significantly after 3 days, but were recovered in higher numbers later in the experiment. Even when infested soil was treated with a $10 \%$ aqueous emulsion, propagules of the pathogen population were detected after 21 days when they were not detected in earlier assays. Treatment of soil did not eliminate $P$. nicotianae, but may have inhibited its ability to germinate on soil dilution plates for a period of time. This observation may be associated with breakdown of the products in soil. The pathogen population still survived, in perhaps low or undetectable numbers, but was able to infect and colonize periwinkle roots and cause disease in the greenhouse over time.
We also observed, in a previous study, that some of these formulations, especially the pepper extract and mustard oil formulations, may have a wide biological effect on other soil microbial populations (3). Other microorganisms also may have been re- duced in numbers (unpublished data), thus allowing for rapid colonization of roots by a small, viable population of propagules of $P$. nicotianae in the absence of competition. Nondetectable propagules of the pathogen may cause disease in this situa-
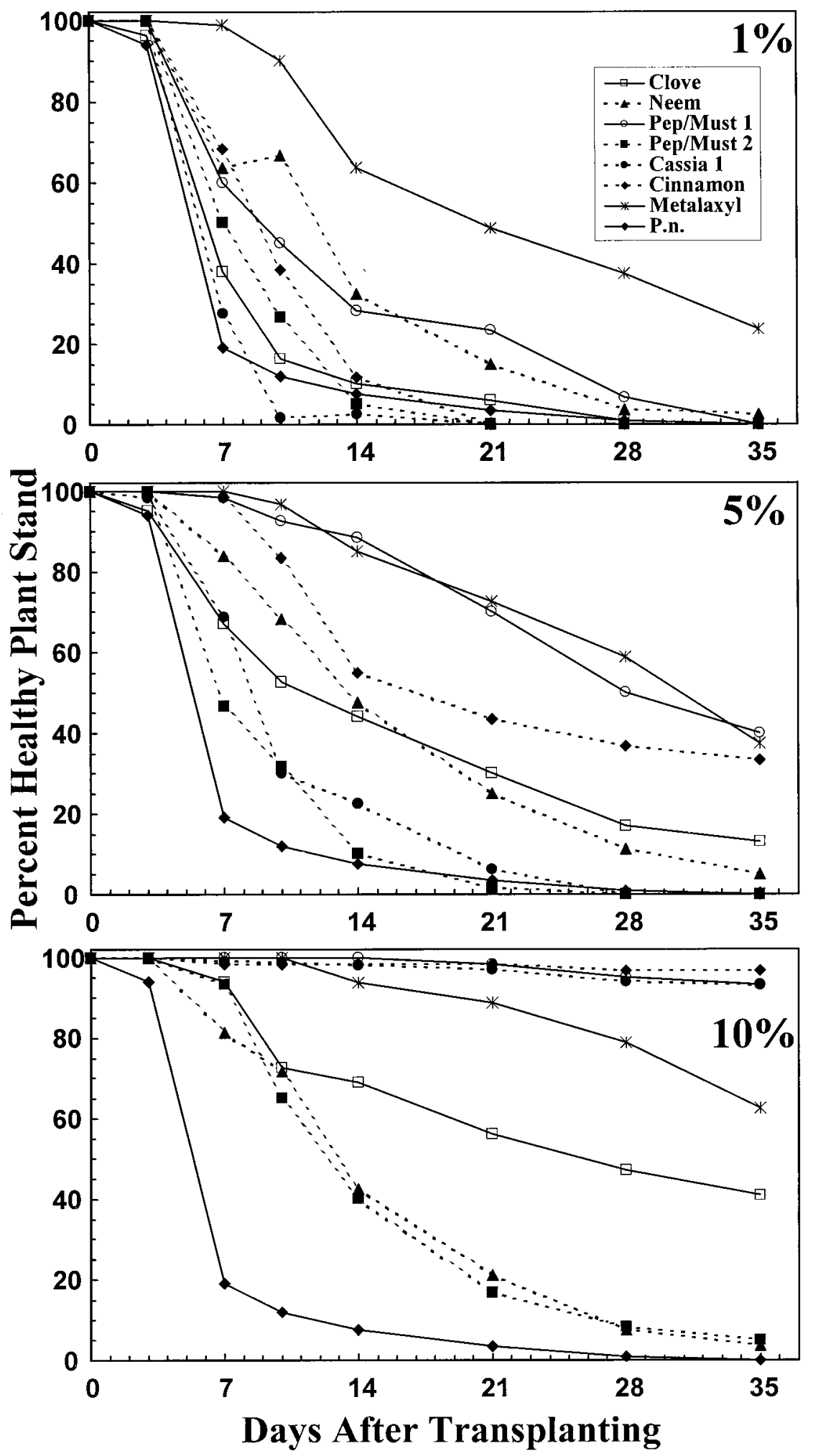

Fig. 2. Percent healthy periwinkle stand after treatment of Phytophthora nicotianae-infested soil with formulated plant extracts and oils or metalaxyl.. Each point represents the mean of repeated trials of the experiment with 20 replications (one plant per pot) per trial. Soil was treated with 1,5 , and $10 \%$ (top, middle, and bottom, respectively) aqueous emulsions of the formulated plant extracts and oils, or with metalaxyl at $0.364,0.728$, and $1.46 \mu \mathrm{l}$ a.i. per $150 \mathrm{~cm}^{3}$ of soil, respectively. 
tion. This may explain the high level of disease in the greenhouse assay for the pepper extract-mustard oil 2 formulation. The pathogen propagule population in soil treated with a $10 \%$ aqueous emulsion of the pepper extract-mustard oil 1 formulation was not detectable in our assay at any time, and presumably reduced pathogen numbers more so than pepper extractmustard oil 2. However, the pathogen was not totally eliminated because there was some disease in the greenhouse assay. Residual inoculum was able to infect and colonize roots of periwinkle, but not to any great degree. Also, if the general microbial community also was reduced, in this instance, to the same relative degree as the pathogen population, then recolonization of the soil by the residual soil microbial community and the microbial processes that accompany recolonization may further inhibit pathogen development by increasing competition on roots from antagonistic microorganisms. We believe that this happened to a greater extent in soil treated with pepper extract-mustard oil 1 than with pepper extract-mustard oil 2. We suggest that very different processes occurred in soil treated with the two pepper extract-mustard oil formulations and, based on our observed results, different factors may affect the pathogen and indigenous soil communities. The pepper extract and mustard oil formulations may have different effects on the pathogen population as well as the indigenous microflora, thus creating a disease-conducive or -suppressive environment. Formulation will have a great effect on the efficacy of any possible product regardless of the mechanism of disease control.

In contrast to the pepper extract and mustard oil formulations, the cassia extract and synthetic cinnamon oil formulations incorporated into soil as $10 \%$ aqueous emulsions were able to control disease effectively at fairly significant pathogen population levels. As before, pathogen populations were not recovered and appeared to decline to below the limit of detection but, over time, were detected in greater numbers. The increase in recoverable pathogen populations did not result in an increase in disease incidence as noted with the pepper extract-mustard oil 2 formulation. As reported earlier, we believe that the cassia extract and synthetic cinnamon oil formulations may not decrease pathogen populations, but increase populations of beneficial microorganisms (3). We observed this phenomenon on dilution plates when recovering $F$. oxysporum from soil. Agar medium was colonized consistently by other fungi in dilution-plate assays of soil treated with the cassia extract. We believe that this mechanism of disease control also may be at work in the $P$. nicotianae-periwinkle pathosystem, although we were not able to observe this with the selective medium used in these experiments. These and alternative hypotheses need to be critically tested, and may explain the results we have seen in two different pathosystems.

The isolate of $P$. nicotianae used in these experiments was very sensitive to metalaxyl, yet the addition of varying rates of metalaxyl to infested soil did not significantly decrease pathogen populations. However, reduced disease incidence was observed in the greenhouse assay. These results indicate that the mode of action of metalaxyl is associated with mycelial growth in the plant and does not act directly on the pathogen propagule in soil $(6,11)$. At the high rate of metalaxyl used in these experiments, healthy plant stand was only $62.5 \% 35$ days after transplanting. The pepper extract-mustard oil 1 formulation, cassia 1 extract, and synthetic cinnamon oil formulations incorporated into soil as $10 \%$ aqueous emulsions resulted in significantly greater stands of healthy plants than the high rate of metalaxyl. Thus, these natural plant formulations may have a role in disease control strategies. Because these materials may be more compatible with the environment than synthetic fungicide treatments, they may not induce pathogen resistance, unlike metalaxyl $(6,11)$.

We have shown that formulated natural plant extracts and oils can reduce pathogen populations and result in higher healthy plant stand in several pathosystems. These formulations, however, need to be researched more fully in several different areas before they may be commercially acceptable. There is no question that these materials are active against a wide range of fungi, and that natural products like these are more environmentally appealing. However, we still know little regarding general nontarget effects and the effects on beneficial soil organisms. In a small field test with some of these materials, we discovered that larger amounts of material were needed when attempting to duplicate effective concentrations in laboratory and greenhouse assays (unpublished data). We do not yet know the economics of applying these formulations on a larger scale, but questions such as formulation and concentration of active ingredients, and how they relate to efficacy and economics, need to be addressed.

\section{LITERATURE CITED}

1. Bowers, J. H., and Locke, J. C. 1998. Effect of botanical extracts on the population density of Verticillium dahliae in soil. (Abstr.) Phytopathology 88:S128.

2. Bowers, J. H., and Locke, J. C. 2000. Effect of botanical extracts in combination with biocontrol organisms on control of Fusarium wilt of muskmelon. (Abstr.) Phytopathology 90:S8.

3. Bowers, J. H., and Locke, J. C. 2000. Effect of botanical extracts on the population density of Fusarium oxysporum in soil and control of Fusarium wilt in the greenhouse. Plant Dis. 84:300-305.

4. Bowers, J. H., and Mitchell, D. J. 1991. Relationship between inoculum level of Phytophthora capsici and mortality of pepper. Phytopathology 81:178-184.

5. Coelho, L., Chellemi, D. O., and Mitchell, D. J. 1999. Efficacy of solarization and cabbage amendment for the control of Phytophthora spp. in North Florida. Plant Dis. 83:293-299.

6. Davidse, L. C. 1988. Phenylamide fungicides: mechanism of action and resistance. Pages 63-65 in: Fungicide Resistance in North America. C. J. Delp, ed. American Phytopathological Society, St. Paul, MN.

7. Erwin, D. C., and Ribeiro, O. K. 1996. Phytophthora Diseases Worldwide. American Phytopathological Society Press, St. Paul, MN.

8. Kannwischer, M. E., and Mitchell, D. J. 1981. Relationships of numbers of spores of Phytophthora parasitica var. nicotianae to infection and mortality of tobacco. Phytopathology 71:69-73.

9. Larkin, R. P., and Fravel, D. R. 1998. Efficacy of various fungal and bacterial biocontrol organisms for control of Fusarium wilt of tomato. Plant Dis. 82:1022-1028.

10. Larkin, R. P., and Fravel, D. R. 1999. Mechanisms of action and dose-response relationships governing biological control of Fusarium wilt of tomato by nonpathogenic Fusarium spp. Phytopathology 89:1152-1161.

11. Lee, T. Y., Mizubuti, E., and Fry, W. E. 1999. Genetics of metalaxyl resistance in Phytophthora infestans. Fungal Genet. Biol. 26:118-130.

12. Mitchell, D. J., Kannwischer-Mitchell, M. E., and Zentmyer, G. A. 1986. Isolating, identifying, and producing inoculum of Phytophthora spp. Pages 63-66 in: Methods for Evaluating Pesticides for Control of Plant Pathogens. K. D. Hickey, ed. American Phytopathological Society, St. Paul, MN.

13. Steel, R. G. D., and Torrie, J. H. 1980. Principles and Procedures of Statistics: A Biometrical Approach. McGraw-Hill, Inc., New York.

14. Tsao, P. H. 1971. Chlamydospore formation in sporangium-free liquid cultures of Phytophthora parasitica. Phytopathology 61:14121413. 